\title{
Construcción de ciudadanía y reconciliación a través del acceso a la justicia
}

\section{Construction of citizenship and reconciliation through access to justice}

\author{
Dr. Francisco Ortega Polanco \\ Pantheón-Sorbonne, Paris I, Francia \\ Franciscoortegapolanco@hotmail.com n https://orcid.org/0000-0002-4428-5306
}

Fecha de recepción: 22 de octubre de 2020

Fecha de aceptación: 5 de noviembre de 2020

Fecha de publicación: 1 de enero de 2021

Favor citar este artículo de la siguiente forma:

Ortega Polanco, F. (2021). Construcción de ciudadanía y reconciliación a través del acceso a la justicia.

AULA Revista de Humanidades y Ciencias Sociales, 2-7

https://doi.org/10.33413/aulahcs.2021.67i1.144

\section{RESUMEN}

La educación es un factor vinculado con la pobreza y con la construcción de ciudadanía plena. $\mathrm{Su}$ significado actual dista en términos geométricos del que tuvo en la Revolución Industrial. La doctrina clásica reduce el concepto a la titularidad de los derechos políticos o cívicos, es decir, participación en la soberanía como elector o elegible a través de elecciones, consultas (referéndum o plebiscito) u otra vía. Es en ese contexto donde alcanza su valor e importancia el acceso a la justicia o tutela judicial efectiva, un principio jurídico de alcance general, cuyo significado es la posibilidad igualitaria de ejercer los derechos o resolver los conflictos a través de la justicia. Es así que concluyo que el acceso a la justicia es la vía más expedita para la construcción de ciudadanía plena, reconciliación social y democracia.

Palabras clave: ciudadanía, derechos, democracia, educación, igualdad, justicia.

\begin{abstract}
Education is a factor linked to poverty and to the construction of full citizenship. Its current meaning is different in geometric terms from the one it had in the Industrial Revolution. The classical doctrine reduces the concept to the ownership of political or civic rights, that is, participation in sovereignty as an elector or eligible through elections, consultations (referendum or plebiscite) or other means. It is in this context that access to justice or effective judicial protection reaches its value and importance, a legal principle of general scope, whose meaning is the equal possibility to exercise rights or resolve conflicts through justice. Thus, I conclude that access to justice is the most expeditious way to build full citizenship and social reconciliation.
\end{abstract}

Keywords: citizenship, democracy, education, equality, justice, rights. 


\section{Introducción}

Ciudadanía es el status de las personas físicas en igualdad de derechos políticos, civiles y económicos, y deberes y obligaciones frente al Estado-nación. Los ciudadanos participan de la soberanía (fuente del poder público). Es concepto vinculado con lo nacional (se es ciudadano -en sentido estricto- con respecto a un Estado nación), pero más amplio; opuesto al de súbdito, ${ }^{1}$ como lo sugiere su exaltación al socaire de las dos grandes revoluciones liberales del siglo XVIII: la francesa, del 14 de julio de 1789 , y la estadounidense, del 4 de julio de1776.

Ciudadanía y democracia son conceptos incluyentes y dependientes. La democracia, sistema político basado en la teoría de la soberanía popular; es decir, elección de los gobernantes por sufragio universal, un gobierno políticamente plural, con prerrogativas limitadas, separación e interdependencia de los poderes públicos, y la garantía de libertades políticas para los ciudadanos. ${ }^{2}$ El gobierno del pueblo, por el pueblo y para el pueblo, cuya piedra angular es el ejercicio efectivo de los derechos y deberes ciudadanos. El goce de la ciudadanía coincide con el nacimiento, pero su ejercicio pleno requiere una capacidad cívica legalmente relacionada con la edad. En América Latina, por ejemplo, 18 años, excepto para los que casaren previamente, y 21 en los Estados Unidos, pero es mucho más que una mera consecuencia cronológica.

Comprende la igualdad jurídica, sujeción de todos al mismo pacto social, salvo las distinciones resultantes del interés general y la voluntad común; inclusión, pertenencia a la unidad política (originalmente la ciudad, modernamente el Estado-nación), dinamismo y contingencia, permanente evolución del significado, conforme confrontaciones económicas, políticas y sociales, y un contrato social eficaz, el individuo goza y está en capacidad material de ejercer derechos y cumplir deberes con respecto al Estado-nación.

La doctrina clásica reduce el concepto a la titularidad de los derechos políticos o cívicos, es decir, participación en la soberanía como elector o elegible a través de elecciones, consultas (referéndum o plebiscito) u otra vía lícita. ${ }^{3}$ El criterio en boga, sin embargo, incluye un aspecto social y otro civil. El social refiere obligaciones y prerrogativas relativas a la seguridad y el bienestar económico, vinculadas a la educación y el servicio público. El civil, es el conjunto de facultades ciudadanas legales dentro de los límites territoriales del Estado, tales como las libertades públicas y los derechos individuales, entre ellos la tutela judicial efectiva o acceso a la justicia. ${ }^{4}$ Los deberes ciudadanos, como contribución con las cargas públicas, la conservación ambiental o la seguridad nacional, son el otro componente básico de la ciudadanía plena.

\section{Ciudadanía y democracia:}

\section{Materia prima de la igualdad}

El ítem por excelencia para determinar la ciudadanía plena es la igualdad jurídica. En las sociedades antiguas, la ciudadanía era un privilegio basado en la riqueza, el poder político, el género o la libertad, estableciéndose categorías de ciudadanos, o sea, de primera, segunda o tercera. En Grecia y Roma, por ejemplo, correspondía a los varones libres y a los que ejercían las armas o un trabajo cualificado. Fue apenas en el 1893, en Nueva Zelanda, cuando la mujer obtuvo el derecho pleno al sufragio. América Latina tardaría otros 31 años. La ecuatoriana Matilde Hidalgo de Prócel fue la primera en hacerlo, específicamente el 09 de junio de 1924 en la ciudad de Loja. Las dominicanas obtuvieron plenitud política con la Enmienda Constitucional de 1942; las mexicanas a partir del 17 de octubre de 1953 y en los Estados Unidos en el 1920, para las personas de raza blanca.

La segregación racial ha sido una constante histórica, en mayor o menor grado, siendo el caso más patético el régimen del Apartheid, en Sudáfrica, donde aún en la última década del siglo XX, unos 25 millones de negros carecían de capacidad cívica plena con respecto a la nación que compartían con tan solo tres millones 
de mestizos, cerca de un millón de indígenas y cinco millones de blancos. La prohibición internacional del comercio de esclavos (trata de negros) data apenas de 1808. Hace solo 147 años desde que Abraham Lincoln decretara el fin de la esclavitud en los Estados Unidos, específicamente, el primero de enero de 1863.

Las luchas de los negros por los derechos de ciudadanía, empero, apenas comenzaban. El Movimiento por los Derechos Civiles, propiamente, surge en los años siguientes a la Segunda Guerra Mundial (1939-1945), en la que un millón de negros estadounidenses combatieron; aunque su punto de partida se considera formalmente el primero de diciembre de 1955, con el arresto en Montgomery, Alabama, de Rosa Lee Parks, por no pararse de su asiento en un autobús para que un hombre blanco se sentara. Martin Luther King, Jr, un joven ministro bautista, lideró un boicot contra el transporte público durante más de un año, obligando a las autoridades a decretar la integración racial en ese servicio. El 28 de agosto de 1963, King, Jr, pronuncia su célebre discurso frente al Monumento a Lincoln, en Washington:

«Tengo un sueño en el que un día, en las rojas colinas de Georgia, los hijos de los ex esclavos y los hijos de los que fueron amos de esclavos, se podrán sentar juntos ante la mesa de la fraternidad». ${ }^{5}$

En 1964, el Congreso estadounidense vota la Ley de los Derechos Civiles, que proscribe la discriminación en lugares públicos e insta a la igualdad laboral y educativa. A finales del siglo XX, persistían, sin embargo, normas segregacionistas. Es apenas el 20 de enero de 2009 (233 años después de la declaración de independencia, 146 del decreto de Lincoln y 46 del discurso de King, Jr.) cuando el primer negro, Barak Hussein Obama, ocupa la Presidencia. ${ }^{6}$

En su obra Patas Arribas. La escuela del mundo al revés; Eduardo Galeano sintetiza el problema de discriminación en América Latina. En 1997 -cuenta-, un automóvil con chapa oficial circula a velocidad normal por una avenida de San Pablo, Brasil. Un policía hace que sus ocupantes se detengan, bajen y por una hora los mantiene manos arriba, de espaldas, mientras les pregunta dónde robaron el vehículo. Los detenidos son Edivaldo Brito, secretario de Justicia del gobierno de San Pablo, y dos funcionarios de la secretaría. Para Brito no había novedad, en menos de un año vivió dicha experiencia cinco veces. Los tres hombres eran negros, el policía que los detuvo también. El otro episodio es el de un diputado mexicano: visitó en el 1986, la Cárcel de Cerro Hueco, en Chiapas, donde encontró a un indio tzotzil, condenado a 30 años de prisión por el degüello de su padre, quien le llevaba, no obstante, tortillas y frijoles cada mediodía. Una paliza había llevado al indio a confesar en una lengua que no entendía bien, que mató a su papá. ${ }^{7}$

La pobreza es otro valladar a la igualdad y por ende a la ciudadanía plena. Los costos en desplazamiento, impuestos y honorarios, colocan el ejercicio de los derechos ciudadanos fuera del alcance de millones de personas. La población latinoamericana bajo la línea de la pobreza promedia un 41.6 por ciento, siendo Haití (con un 75.0 por ciento), Honduras (con un 69.0), Nicaragua (con un 62.0) y Paraguay (con un 61.0) los casos más graves; mientras Chile, Uruguay, Costa Rica y Argentina promedian un porcentaje de 18.0. En México se estima que un 32.0 por ciento vive en pobreza extrema, y en República Dominicana, un 45.0 por ciento. El $20.0 \%$ de los latinoamericanos recibe casi el 60 por ciento del ingreso total, mientras que el 20 por ciento más pobre, solo el 3.0 por ciento. Ningún país de la región integra el G-8, es decir el grupo de las naciones más ricas del mundo (Estados Unidos, Gran Bretaña, Francia, Alemania, Canadá, Italia, Rusia y Japón). En el G-20, que incluye las economías emergentes, solo participan México, Brasil y Argentina. ${ }^{8}$

La educación es un factor vinculado con la pobreza y con la construcción de ciudadanía plena. Su significado actual dista en términos geométricos del que tuvo en la Revolución Industrial. A los estándares básicos se les agregan 
el dominio de la informática y por lo menos un segundo idioma. La advertencia del presidente Obama de que la mayoría de los trabajadores requerirán educación superior para las demandas laborales del siglo XXI ${ }^{9}$ trasciende las fronteras. La fuerza de trabajo depende, como en ninguna otra etapa de la historia, del conocimiento. En América Latina, entre el 72 y el 96 por ciento de los jefes de hogar de las familias pobres, promedian menos de nueve años de educación formal. El adulto medio ubicado entre el 10 por ciento más rico supera por lo menos con siete años de educación formal al adulto situado entre el 30 por ciento más pobre; la inversión en educación es seis veces menor, en términos proporcionales, que la de los países industrializados, pese a que éstos solo albergan al 25 por ciento de la gente que estudia; mientras que en los países de la región está el restante 75 .

La proporción del gasto público para la educación en América Latina oscila entre un 12 $\mathrm{y}$ un 22 por ciento, equivalente a un 4 por ciento del Producto Interno Bruto (PIB), de lo cual, entre el 70 y el 90 por ciento corresponde al gasto en personal. ${ }^{10}$

\section{La tarea de la democracia}

La reconciliación, por su parte, se refiere a la búsqueda entre opuestos de una relación pacífica. Según el contexto, aplica a diferentes situaciones, pero en todo caso plantea la recuperación de espacios pacíficos para la negociación entre sectores enfrentados por razones políticas o económicas, o por el colapso del pacto social. Los conflictos armados en República Dominicana en 1965, en Nicaragua o El Salvador en la década de los 80, y más recientemente en México y Colombia; y en menor proporción las luchas nacionales derivadas de la tirantez entre la antigua URSS y las potencias occidentales, tras la Segunda Guerra Mundial, en el período de la Guerra Fría, plantean una reconciliación en términos más concretos.

Al margen de los conflictos activos propiamente, la necesidad de conciliación surge de una confrontación más difusa, connatural a la sociedad, producto de la lucha de clases, los intereses encontrados, la escasez de recursos estratégicos y la movilidad social, que es la razón de ser del establecimiento de un pacto social, manifiesto, por ejemplo, en la Constitución.

Confrontación y reconciliación son dos fenómenos continuos, de manera que es tarea de la democracia resolver pacíficamente el conflicto, pues el ser humano es naturalmente social, cuyos impulsos e instintos lo inducen a reconstituir el orden social tantas veces como fuese quebrantado, tesis aristotélica secundada por la ciencia social contemporánea. ${ }^{11}$

Es así como la construcción de la ciudadanía plena y la reconciliación social son labores perennes e inconclusas, que a veces asemejan a las sociedades con la leyenda de Sísifo, aquel personaje mitológico condenado a empujar una roca por una pendiente, dejarla rodar desde la cúspide y reiniciar continuamente su tarea. Es en ese contexto donde alcanza su valor e importancia el acceso a la justicia o tutela judicial efectiva, un principio jurídico de alcance general, cuyo significado es la posibilidad igualitaria de ejercer los derechos o resolver los conflictos a través de la justicia. Implica la opción del ciudadano de llegar hasta el juez o tribunal al margen de su condición económica, social o política; la respuesta oportuna y justa del órgano judicial, y la ejecución cabal y sin obstáculos de su resolución. La Declaración Universal de los Derechos Humanos (artículo 10), la Convención Americana de los Derechos Humanos (artículo 1), el Pacto Internacional de Derechos Civiles y Políticos (artículo 14), la jurisprudencia de la Corte Interamericana de Derechos Humanos (15) y las constituciones políticas de todos los países de América Latina, consagran el acceso igualitario, gratuito y efectivo a la justicia, el amparo general, el habeas corpus, el habeas data, los intereses colectivos o difusos, la independencia e imparcialidad judicial, la celeridad de los procesos y el control temporal, entre otros mecanismos para hacer efectiva esa garantía. 


\section{La fuerza al servicio de la justicia}

El problema es que no vivimos dentro de la letra del derecho y esos valores no se construyen desde la retórica de los estrados o del capitolio. Millones de personas incurren cotidianamente en el ilícito de porte ilegal de apariencia, condición económica u origen social, mientras ocurre la sempiterna disputa entre la fuerza del derecho y el derecho de la fuerza. Si como se ha dicho lo que es fuerte es lo que es de derecho, ${ }^{12}$ entonces el desafío de los Estados es poner la fuerza al servicio del acceso efectivo a la justicia.

El 4 de septiembre de 1957, Elizabeth Eckford, Melba Pattillo Veals, Ernest Green, Gloria Ray Karlmark, Carlotta Walls La Nier, Terrence Roberts, Jefferson Thomas, Minninjean Browm Trickey y Thelma Mothershed Fair, muchachos entre 15 y 16 años, asistieron a la escuela secundaria central en Little Rock, Arkansas, Estados Unidos; hasta entonces reservada para niños blancos, como parte del plan de integración escolar derivado del precedente Brown Vs. Junta de Educación, que prohibió la segregación racial en las escuelas. El gobernador

\section{Referencias}

Capitant, H. (s.f.). Vocabulario jurídico. Ediciones Depalma. Cincotta, H. (1994). Reseña histórica de los Estados Unidos. Servicio cultural e informativo de los Estados Unidos.

Duverger, W. (1992). Instituciones politicas y derecho constitucional. Colección DEMOS, Ediciones Ariel.

Farías Campos, F. (2002). Estudio comparado de las instituciones politicas nacionales latinoamericanas. s.n.

Fukuyama, F. (1999). La gran ruptura. La naturaleza humana y la reconstrucción del orden social. Editorial Atlántida.

\section{Notas}

${ }^{1}$ Vea La democracia en América Latina Hacia una democracia de ciudadanas y ciudadanos. Programa de las Naciones Unidas para el Desarrollo (PNUD), 2004.

${ }^{2}$ Duverger, W. (1992). Instituciones políticas y derecho constitucional. Colección DEMOS, Ediciones Ariel, p.70.

${ }^{3}$ Capitant, H. Vocabulario jurídico. Ediciones Depalma. Argentina, p.113. Ortega Polanco, F. (2009). Diccionario jurídico 9-11 (Abogado d' bolsillo). Editora Corripio, CxA, p.309.
Orval Faubus ordenó a la Guardia Nacional, so pretexto de amenazas de violencia, impedirles la entrada. Una corte ordenó el retiro de las tropas, pero cuando los chicos volvieron a la escuela, tuvieron que regresar a casa entre burlas, vejámenes y estridencia racial. El 25 de ese mismo mes, los Nueve de Little Rock retornaron definitivamente, entonces escoltados por soldados de la División Aerotransportada No. 101 del Ejército Federal, por disposición del presidente Dwight D. Eisenhower. ${ }^{13}$

\section{Conclusión}

El acceso a la justicia es la vía más expedita para la construcción de ciudadanía plena y reconciliación social. La experiencia universal nos enseña, sin embargo, que no basta su vigencia literal en convenciones internacionales o en las constituciones nacionales. Hace falta la voluntad de hacerlo creíbles y confiables, sobre todo en nuestro mundo, paradójicamente en bancarrota, aun en el apogeo de la era informática, con su despliegue jamás imaginado de maravillas tecnológicas y de riqueza material.

Galeano, E. (1999). Patas arriba. La escuela del mundo al revés. Siglo XXI. Editores S.A.

Martínez Ruiz, J. (Azorín). (2013). El político. Fondo de cultura económica.

Obama, B. (2006). La audacia de la esperanza. Vintage Español.

Ortega Polanco, F. (2009). Diccionario jurídico 9-11: Traducción popular del lenguaje de la justicia. Editora Corripio, $\mathrm{C}$ x A.

${ }^{4}$ Véase Marsshal, T.H. 1965. «Citizenship and Social Class», en Marshall, T.H. (Comp). «Class, Citizenship and Social Develoment», Nueva York. Garden City, Doubleday (1949), citado por Programa de las Nacional Unidas para el Desarrollo (PNUD), La Democracia en América Latina, 2004.

${ }^{5}$ Farías Campos, Félix. Estudio comparado de las constituciones políticas nacionales latinoamericanas. Santo Domingo, 2002. 
${ }^{6}$ Código Penal de la República Dominicana. Artículo 336. Vea Ortega Polanco, F., op.cit., p.324.

${ }^{7}$ Galeano, Eduardo. Patas Arriba. La escuela del mundo al revés. Siglo XXI, Editores S.A. España, septiembre 1999, p.59.

${ }^{8}$ Informe de la Comisión Económica para América Latina (CEPAL), Panorama Social 2008. Citado por Diálogo Interamericano, Policy Briet, noviembre 2009, Citado por Espinal, Rosario. Periódico Clave, jueves 5 de noviembre de 2009, p.24.

${ }^{9}$ Obama, Barak. La audacia de la esperanza. Vintage Español, Nueva York. 2006, p.175.
${ }^{10}$ Organización de las Naciones Unidas (ONU), CEPAL, UNESCO. Informe financiamiento y gestión de la educación en América Latina y el Caribe trigésimo período de sesiones de la CEPAL, San Juan, Puerto Rico, 28 de junio-02 de julio de 2004.

${ }^{11}$ Fukuyama, F. La gran ruptura. (1999). La naturaleza humana y la reconstrucción del orden social. Editorial Atlántida, pp.19-47.

${ }^{12}$ Martínez Ruíz, José (Azorín). 1873-1967. El político. Capítulo XV.

${ }^{13}$ Cincotta, Howard. Reseña histórica de los Estados Unidos. Servicio Cultural e Informativo de los Estados Unidos, marzo, 1994.

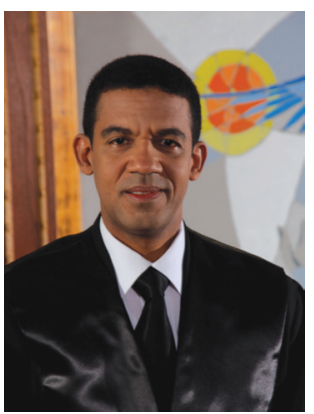

Francisco Antonio Ortega Polanco

Juez de la Corte Suprema de la República Dominicana (Sala Penal). Doctor en Derecho por la Universidad de Salamanca, España. Máster en Derecho Administrativo y en Derecho Constitucional, por las universidades de Salamanca, España, y la Universidad Pantheón-Sorbonne, París I, Francia, y por el Instituto Global de Altos Estudios (Iglobal). Licenciado en derecho, Cum Laude, por la Universidad Nacional Pedro Henríquez Ureña (UNPHU). Especialidad en Derecho Tributario, por la Escuela Nacional de la Judicatura. Profesor colaborador para los cursos de especialización de la Universidad de Salamanca. Autor de unos diez libros de ciencias jurídicas y cultura general. Expositor en los seminarios internacionales sobre Estándares Interamericanos del Derecho de Acceso a la Información Pública (Bogotá, D.C, Colombia), y temas esenciales de Justicia y Mejores Prácticas Ciudadanas en América (México, D.F., México). 